\title{
Dynamic Hygrothermal Analysis of Moisture Bridges in Modern Masonry Constructions
}

\author{
Balázs Nagy ${ }^{l}$ \\ ${ }^{1}$ Budapest University of Technology and Economics, Faculty of Civil Engineering, Department of \\ Construction Materials and Technologies, Müegyetem rkp. 3. K.I.85, 1111 Budapest, Hungary
}

\begin{abstract}
Building material manufacturers have already started to develop new products to prepare for the nearly zero energy performance requirements, which will have serious effects on the masonry industry. In recent years, masonry manufacturers started to produce blocks filled with thermal insulation material to increase the thermal resistance of bricks, and to sell insulation together with the masonry blocks. These blocks are used in new constructions across Central-Europe with different geometry and fillers; however, many of their properties, such as hygrothermal behaviour is not yet researched in details neither the blocks, nor in building constructions. In this paper, I present a new approach to evaluate the moisture performance of building constructions. I defined moisture transmittance and moisture bridges of building constructions to evaluate their hygrothermal performance. By using monthly based hygrothermal simulations and analysing thermal and moisture transmittance, linear thermal and moisture transmittance and effective water vapour diffusion resistance factors, I showed how the hygrothermal performance of the thermal insulation filled masonry blocks varies on monthly basis and showed that even when the thermal insulation filler does not have any significant effect on the thermal performance of the blocks, it could have serious effects on the moisture performance of the blocks.
\end{abstract}

\section{Introduction}

Compared to thermal performance studies dealing with thermal insulation filled masonry blocks, the number of scientific papers dealing with hygrothermal approach on hollow and filled masonry blocks is very limited. A study of the hygrothermal behaviour of textile based insulation filled masonry blocks by Zach et al. (2013). They evaluated the temperature and relative humidity distributions in the filled blocks by using WUFI 2D software. Pavlík et al. (2015) performed an experiment with their semi-scale device (Pavlik et al., 2002) on mineral wool filled masonry blocks. The studied brick block was exposed to different hygrothermal climatic conditions. On the exterior side winter conditions corresponding to the reference climatic year of Prague, Czech Republic were applied, while on the interior side the conditions of a residential house were simulated. Based on the temperature and relative humidity profiles monitored across the studied brick sample having the real thickness of a single-layer building envelope, they concluded that the hygrothermal performance of the blocks filled with mineral wool is satisfactory. Hou et al. (2017) presented a coupled heat and moisture transfer analysis of hollow concrete blocks filled with compressed straw bricks. They built a controllable heat and moisture testing device, which was similar to Pavlík's one. After they performed measurements on the filled blocks and analysed the collected temperature and relative humidity data measured by sensors across a section, they developed a one-dimensional hygrothermal software that was capable of coupled heat and moisture transfer simulation, and implemented the tested cross section into it. The simulations showed good agreement with the experiments. Maděra et al. (2017) published their hygrothermal approach on the studied insulation filled masonry block by using Künzel's model (Künzel, 1995) with a small modification of introducing the global moisture transport function, which incorporates both vapour and liquid transports. They handled the hygrothermal simulations with decomposed geometry, which resulted shorter simulation time. Krejčí et al. (2017) also published research about numerical analysis of coupled heat and moisture transport in masonry. Their work, among others, contained a 2D hygrothermal analysis of thermal insulation filled masonry blocks, which had the same geometry as researched by Madera et al. in their studies. Krejčí et al. (2017) compared three simulation approaches, a classical finite element solution, a domain decomposition method with 20 subdomains, and the processor farm method also with 20 subdomains. They performed 1800 time steps on the models, and compared the simulation times by a high end simulation workstation. The FEM based approach needed the longest time to solve the problem, 4 days. The two subdomain using methods ended the task after "only" 10 hours and 15 hours, respectively. This study showed that parallelization of calculation processes is very important. In recent years, thermal insulation filled masonry blocks have been studied on the basis of laboratory measurements (Nagy and Orosz, 2015), steady-state (Nagy and Stocker, 2019) and time dependent (Nagy and Tóth, 2016) numerical simulations, respectively. Based on previous research on hygrothermal performance of masonry blocks, I thought we need a method, that provide easily comparable results to evaluate the moisture transport behaviour of complex building elements and construction joints, besides analysing their simulated moisture content or relative humidity, which is now the 
standard methodology in these evaluations. These analyses are only available when we perform time dependent, hourly based simulations, which can be demanding to handle due to the increased need of computational efforts and necessary material properties. The method I came up with to analyse the moisture performance is somewhat similar to the method we use to deal with thermal problems and works by using steadystate approach, however it is conducted on monthly basis, which makes it suitable to evaluate how these blocks perform over changing boundary conditions. I introduced moisture transmittance and linear moisture transmittance of building constructions.

\section{Methods}

\section{Numerical model}

In this paper, monthly based steady-state conjugated heat and moisture transfer (HAM) simulations were carried out. Steady-state equations are time-independent, and cannot take the heat and moisture capacity of the materials into account; however, they have the advantage that their runtime is significantly shorter and it needs significantly less material data, which is also missing from the technical datasheets of these products. In my approach, thermal conductivity of the materials is temperature and volumetric moisture content dependent, which means that moisture transfer will affect heat transfer, therefore moisture storage curves of the materials are needed to perform the simulations. Partial differential equation (PDE) of steady-state heat transfer is shown by Eq. (6), in which the first member represents heat fluxes from heat conduction and the second part shows heat fluxes from evaporation flux. If only heat transfer is considered in the numerical model, then only the first member was used for the simulation. In Eq. (6), $\nabla=\left(\frac{\partial}{\partial x}, \frac{\partial}{\partial y}, \frac{\partial}{\partial z}\right)$ is nabla vectorial differential operator, $\mathbf{q}$ is heat flux $\left[\mathrm{W} / \mathrm{m}^{2}\right]$, $\lambda_{\text {eff }}=\lambda_{10, \text { dry }} \cdot e^{f_{T}\left(T_{2}-10^{\circ} \mathrm{C}\right)} \cdot e^{f_{\psi}\left(u_{2}\right)}$ is temperature and volumetric moisture content dependent effective thermal conductivity [W/mK], based on MSZ EN ISO 10456. $T$ is temperature $[\mathrm{K}], L_{v}$ is latent heat of evaporation of water $[\mathrm{J} / \mathrm{kg}], \delta_{p}=\delta_{a} / \mu$ is vapor permeability $[\mathrm{kg} / \mathrm{msPa}]$, in which $\delta_{a}$ is the vapor permeability of still air depending on air temperature and $\mu$ is the vapor resistance factor [1], $\varphi$ is relative humidity [1] and $p_{\text {sat }}$ is the saturation pressure of water vapor [Pa], depending on temperature:

$\nabla \mathbf{q}=\nabla\left[\lambda_{\text {eff }} \nabla T+L_{v} \delta_{p} \nabla\left(\varphi p_{\text {sat }}(T)\right)\right]=0$.

The PDE of steady-state moisture transfer is defined by Eq. (7), in which the first member of the equation represents the liquid transport of moisture fluxes, while the second part is responsible for moisture fluxes from vapour transport:

$\nabla \mathbf{g}=\nabla\left[\xi D_{w} \nabla \varphi+\delta_{p} \nabla\left(\varphi p_{\text {sat }}(T)\right)\right]=0$.

In Eq. (2), $\mathbf{g}$ is moisture flux $\left[\mathrm{kg} / \mathrm{m}^{2} \mathrm{~s}\right], \xi=\frac{\partial \mathrm{w}}{\partial \varphi}$ is differential moisture capacity $\left[\mathrm{kg} / \mathrm{m}^{3}\right]$, which can be represented as the slope of the moisture storage function between different relative humidity values, where $\mathrm{w}$ is the moisture content $\left[\mathrm{kg} / \mathrm{m}^{3}\right]$ according to the moisture storage function of the materials. $D_{w}$ is the liquid transport coefficient $\left[\mathrm{m}^{2} / \mathrm{s}\right]$. Steady-state simulation was chosen in some cases instead of performing time-dependent hourly based simulations because of the main goal of the research was to compare thermal and moisture transmittances and linear thermal- and moisture transmittances of the building constructions considering monthly design conditions, and also to evaluate the effect of neglecting moisture transfer. For evaluating linear thermal transmittances of building construction, usually thermal only approach is considered nowadays (Bakonyi and Dobszay, 2014); however, considering conjugated moisture transport would increase the heat losses of components. The partial differential equations shown by Eq. (1) and Eq. (2) were implemented into COMSOL Multiphysics.

\section{Geometry}

In this study, wall constructions are handled with their complex geometries, which contain their inner structures as well. This detailed modelling makes it possible to analyse the building constructions in their depths and get deeper understanding about their hygrothermal behaviour. Detailed 2D geometry models of the evaluated horizontal wall corner section made of $44 \mathrm{~cm}$ thick insulation filled masonry blocks is shown in Fig. 1.

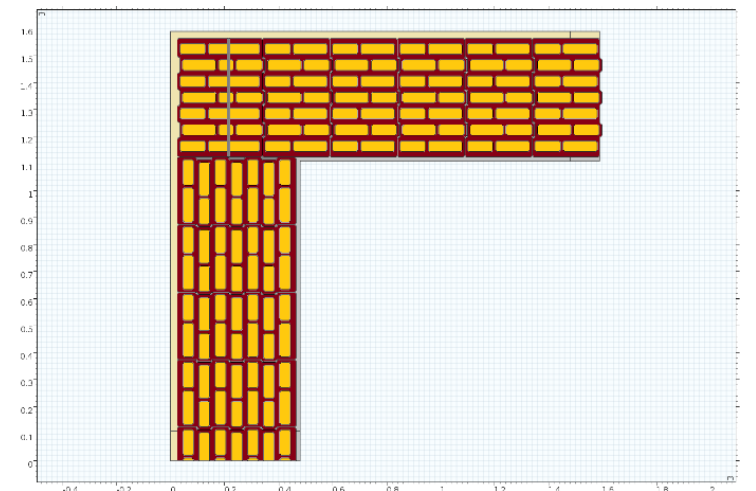

Figure 1: Model of masonry wall corner joint.

\section{Material properties}

Material properties of the tested thermal insulations, aerogel blanket (AG), polyurethane foam (PUR), mineral wool (MW), expanded polystyrene (EPS) and expanded perlite (EXP), as well as fired clay (FC), the $15 \mathrm{~mm}$ thick internal plaster (IP) and the $20 \mathrm{~mm}$ thick external plaster (EP) are listed in Table 1, and were measured in laboratory (Nagy and Stocker, 2019) and summarized in Table 1, while sorption isotherms are shown by Fig. 2-3.

Table 1: Material properties (Nagy and Stocker, 2019).

\begin{tabular}{|c|c|c|c|c|}
\hline Material & $\begin{array}{c}\boldsymbol{\lambda}_{\mathbf{1 0}, \mathbf{d r y}} \\
{[\mathbf{W} / \mathbf{m K}]}\end{array}$ & $\begin{array}{c}\mathbf{f}_{\mathbf{T}} \\
{[\mathbf{1} / \mathbf{K}]}\end{array}$ & $\begin{array}{c}\mathbf{f}_{\boldsymbol{\psi}} \\
{\left[\mathbf{m}^{\mathbf{3}} / \mathbf{m}^{\mathbf{3}}\right]}\end{array}$ & $\begin{array}{c}\boldsymbol{\mu}_{\text {dry/wet }} \\
{[-]}\end{array}$ \\
\hline AG & 0.012 & 0.0015 & 3 & 4.5 \\
\hline PUR & 0.024 & 0.0055 & 6 & $80 / 70$ \\
\hline MW & 0.031 & 0.0045 & 4 & 1.3 \\
\hline EPS & 0.037 & 0.0035 & 4 & $70 / 30$ \\
\hline EXP & 0.050 & 0.0035 & 3 & 2 \\
\hline FC & 0.35 & 0.001 & 10 & $15 / 10$ \\
\hline IP & 0.40 & 0.001 & 3 & 8.1 \\
\hline EP & 0.09 & 0.001 & 8 & 8.3 \\
\hline \multicolumn{5}{|r}{}
\end{tabular}




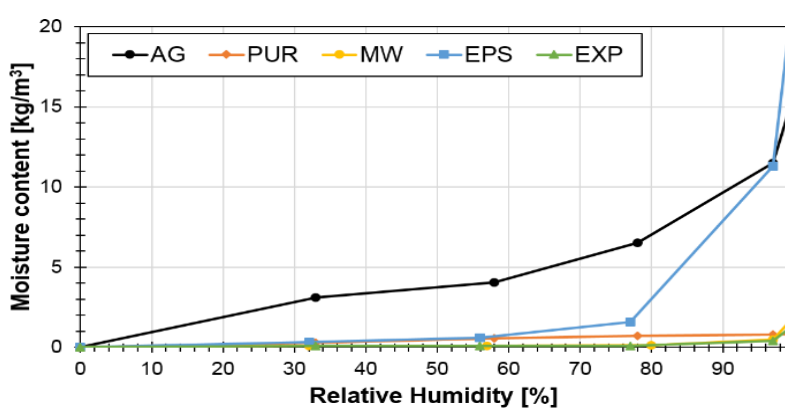

Figure 2: Sorption isotherms of thermal insulations

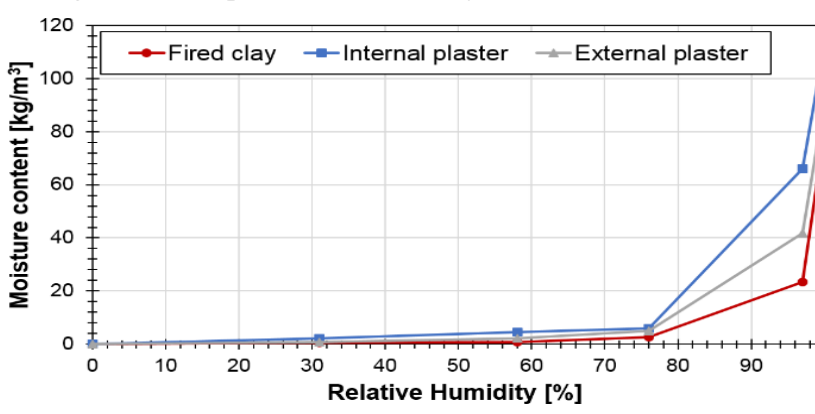

Figure 3: Sorption isotherms of FC, IP and EP.

\section{Boundary conditions}

I used monthly averaged temperature and relative humidity values for the basis of the boundary conditions from weather files. The hourly based multi-year (19912010) averaged weather file of Budapest were obtained from Meteonorm 7. Although Meteonorm can take some corrections on the weather data into account depending on its situation, and I used city situated weather files, microclimate or the effect of vegetation, such as windfield around the buildings (Szkordilisz and Zöld, 2016), or the local environment (Gao et al., 2017) haven't studied in the presented paper. From the created hourlybased weather files, monthly averages were calculated and used for the basis of external boundary conditions. As shown later, there is no $80 \%$ or higher external relative humidity in the average monthly values, therefore liquid transport does not play significant role within the masonry blocks besides vapour diffusion. Internal conditions of air, and equivalent vapour diffusion thicknesses of the boundary layers were set according to the MSZ EN 15026, which uses the external temperature to define both internal temperature and internal relative humidity. In simulations, normal occupancy was considered. Surface heat transfer coefficients were set based on MSZ EN ISO 6946. The heat transfer coefficients were set to $h_{s i}=7.69$ $\mathrm{W} / \mathrm{m}^{2} \mathrm{~K}$ for internal and $\mathrm{h}_{\mathrm{se}}=25 \mathrm{~W} / \mathrm{m}^{2} \mathrm{~K}$ for external surfaces, and the equivalent vapour diffusion thickness of boundary layer was set to $\mathrm{s}_{\mathrm{d}, \mathrm{si}}=0.008 \mathrm{~m}$ on the internal and $\mathrm{s}_{\mathrm{d}, \mathrm{se}}=0.0023 \mathrm{~m}$ on the external surface according to MSZ EN 15026.

\section{Moisture transmittance}

Besides calculating thermal and linear thermal transmittance according to MSZ EN ISO 10211, to characterize the moisture behaviour of a building element, I introduced and defined $\mathrm{M}\left[\mathrm{kg} / \mathrm{m}^{2} \mathrm{sPa}\right]$ moisture transmittance value. $\mathrm{M}$ value can be calculated according to the formula presented by Eq. (3), as the ratio of $G$ internal surface moisture flow through $1 \mathrm{~m}^{2}$ of internal surface of the building element and $\Delta p$ water vapour pressure difference, or by the ratio of $g$ moisture flux and the water vapour pressure difference:

$\mathrm{M}=G /(A \cdot \Delta p)=g / \Delta p$.

If a building element can be simplified to one layer and considered homogeneous, and if it does not consist of any capillary active material, then moisture transmittance, presented by Eq. (3), equals to the vapour permeability multiplied by $1 \mathrm{~m}$ length. From this, effective water vapour diffusion resistance factor can be easily defined, as dividing vapour permeability of air by the building element specific value. Calculation of the moisture transmittance of complex, inhomogeneous building elements could only have carried out effectively by using conjugated heat and moisture transport numerical simulation. For characterization of moisture bridges, introduction of the linear moisture transmittance is necessary, which is designated as Greek letter $v$, and can be determined in a similar way to the linear thermal transmittance, see Eq (4). This factor shows how many kilograms of additional moisture can flow through one running meter of a construction joint within a second comparing to the moisture transmittance of the connecting building elements measured at the internal length:

$v=G /(l \cdot \Delta p)-\sum_{j} M_{j} \cdot l_{j}$

Based on Eq. (3) and Eq. (4), it can be seen that for the calculation of the moisture transmittances, $G$ moisture flow on the internal surface of the building structure, caused by the $\Delta p$ water vapour pressure difference, has to be determined. The water vapour pressure difference can be calculated by using Eq. (5) from $\theta$ air temperature $\left[{ }^{\circ} \mathrm{C}\right]$ and $\varphi$ relative humidity of the separated spaces (e.g. internal and external space):

$\Delta p=\varphi_{i} \cdot p_{\text {sat }}\left(\theta_{i}\right)-\varphi_{e} \cdot p_{\text {sat }}\left(\theta_{e}\right)$.

Water vapour pressure of saturated air can be obtained by MSZ EN ISO 13788 illustrated by Fig. 4.

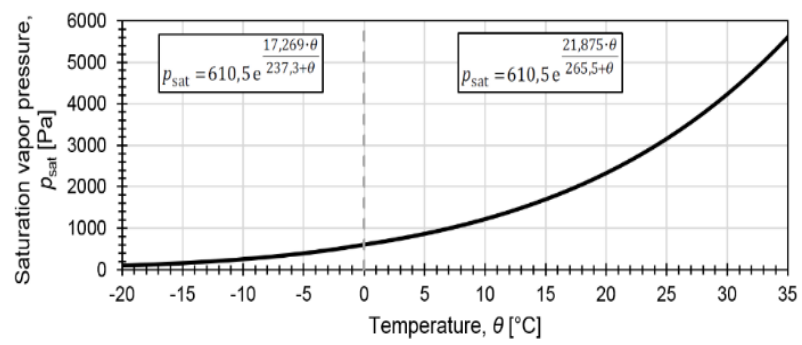

Figure 4: Saturation vapour pressure as a function of temperature according to MSZ EN ISO 13788.

\section{Results and discussion}

Due to limitations of the presented paper, I summarize my approach by comparing thermal and moisture transmittances and water vapour diffusion resistance factors of walls and wall corner joints. The monthly based simulations are illustrated by Fig. 5-8, which figures show a wall corner joint made of PUR and MW filled masonry blocks in Budapest, in January month. Temperature, heat flux, relative humidity and moisture flux was retrieved monthly and analysed across the sections. 
a)

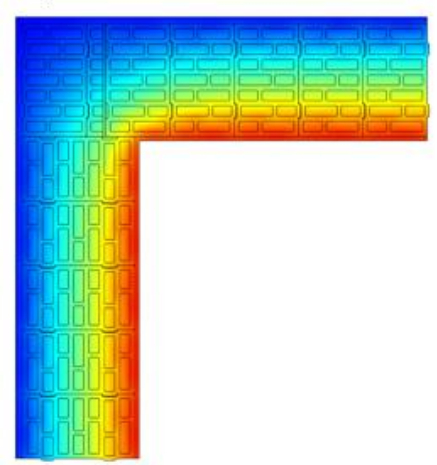

b)

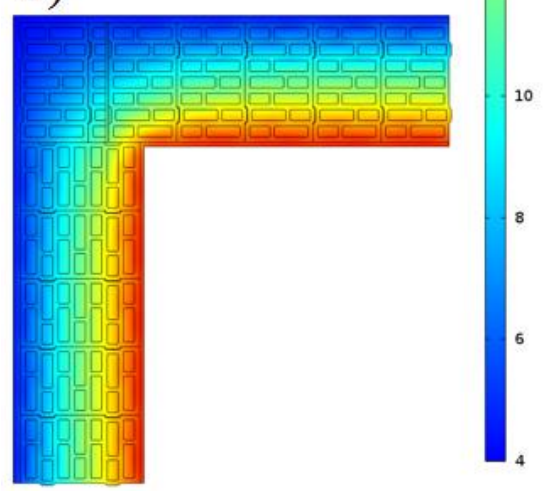

Figure 5: Temperature $\left[{ }^{\circ} \mathrm{C}\right]$ distribution of a wall corner in January, Budapest, made of PUR (a) and MW (b) thermal insulation filled masonry blocks.

a)

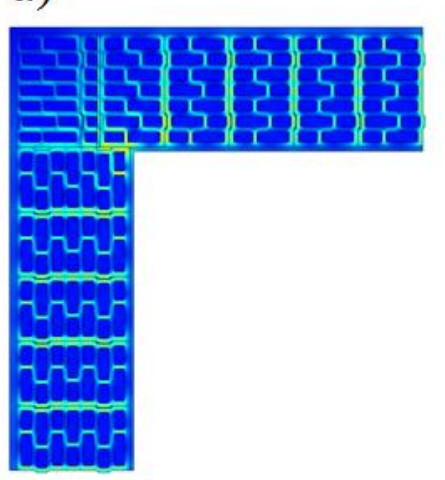

b)

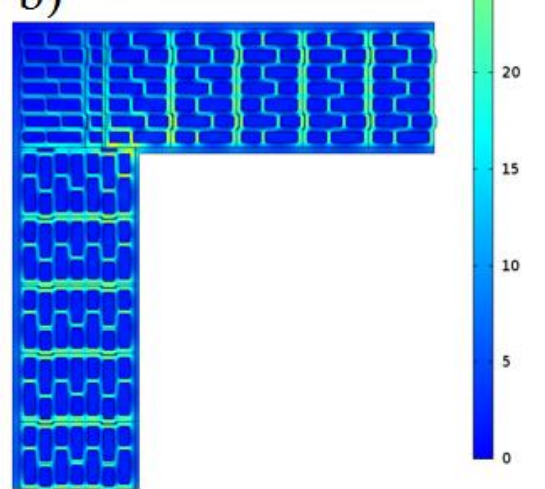

Figure 6: Heat flux magnitude $\left[\mathrm{W} / \mathrm{m}^{2}\right]$ distribution of a wall corner in January, Budapest, made of PUR (a) and $M W(b)$ thermal insulation filled masonry blocks. a)
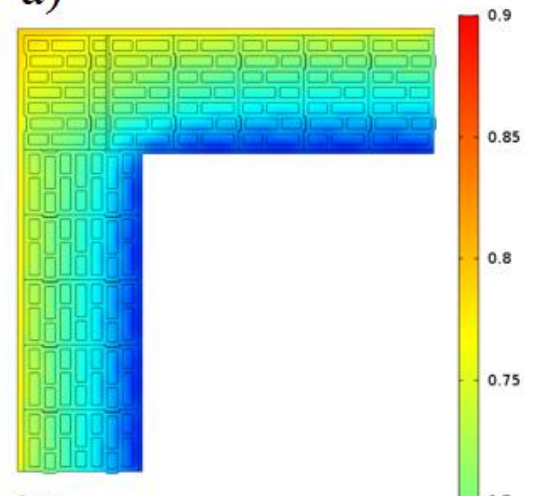

b)

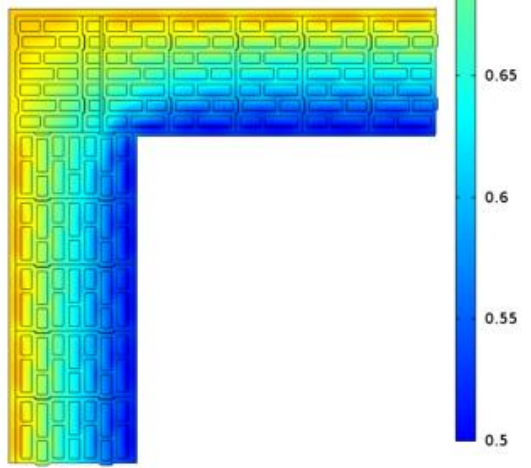

Figure 7: Relative humidity [1] distribution of a wall corner in January, Budapest, made of PUR (a) and MW (b) thermal insulation filled masonry blocks.

\section{a)}

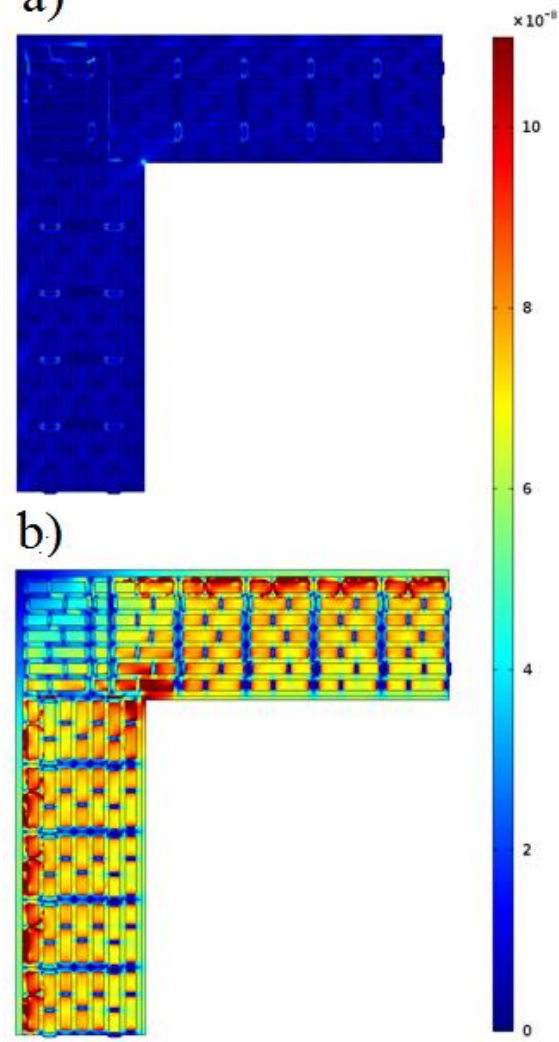

Figure 8: Moisture flux magnitude $\left[\mathrm{kg} / \mathrm{m}^{2} \mathrm{~s}\right]$ distribution of a wall corner in January, Budapest, made of PUR (a) and $M W(b)$ thermal insulation filled masonry blocks. 
It is visible on Fig. 5, that although there is significant difference between the thermal conductivity of the filler materials, there is no observable difference between the temperature distribution within the masonry blocks and even the surface temperatures in the corner are differs only within only $0.5{ }^{\circ} \mathrm{C}$ considering all fillers. This also means that evaluating the temperature factor according to MSZ EN ISO 13788 in the corners gives very similar results, therefore it is not suitable to compare hygrothermal performance and behaviour of the different fillers. There is also negligible difference, when we compare heat flux magnitudes in the simulated cross sections of the wall corner joints shown by Fig. 6. Heat flux magnitudes show good agreement, only their values vary slightly. Comparing relative humidities of the PUR and MW filled blocks show differences shown by Fig. 7., which is observable mostly in the outermost insulation layers of thermal insulation. While PUR show continuous transition between the colours representing the relative humidity field between 0.5-0.9, MW filler show lower relative humidities in the innermost insulation layer and moisture accumulation in the outermost layer next to the fired clay walls closer to the external surface. This means that while PUR blocks the way of the moisture flow because of its low vapour permeability, MW allow the moisture flow through easily. Last but not least, Fig. 8 shows the moisture flux magnitudes across the sections. This figure shows clearly how PUR and MW filled masonry blocks behave differently against moisture flows. While PUR filled blocks show low moisture flux magnitudes across the sections due to the low permeability of PUR, masonry blocks containing MW performs very differently. It is also visible that in the inner corner and in the MW outermost insulation layer, moisture flux magnitude rises.

In Table 2, thermal and moisture transmittances of the adjoining walls (without the geometrical thermal bridging) and linear thermal and moisture transmittances of the wall corner joint as well as the effective water vapour diffusion resistance factor of the wall and wall corner is shown by their heating season (NovemberMarch) averaged values. It is clearly visible, that while there are only slight differences between $U$ and $\psi$ values, differences are greater by magnitudes between PUR and MW filled masonry blocks in the case of $\mathrm{M}$ and $v$ values.

Table 2: Results of the comparative analysis of thermal and moisture transmittances of wall corner joints made of PUR and MW filled masonry blocks in heating season, Budapest.

\begin{tabular}{|c|c|c|}
\hline Case & PUR filler & MW filler \\
\hline $\mathrm{U}_{\text {wall }}\left[\mathrm{W} / \mathrm{m}^{2} \mathrm{~K}\right]$ & 0.179 & 0.195 \\
\hline$\psi_{\text {corner }}[\mathrm{W} / \mathrm{mK}]$ & 0.088 & 0.091 \\
\hline $\begin{array}{c}\mathrm{M}_{\mathrm{wall}} \cdot 10^{-12} \\
{\left[\mathrm{~kg} / \mathrm{m}^{2} \cdot \mathrm{s} \cdot \mathrm{Pa}\right]}\end{array}$ & 3.74 & 24.06 \\
\hline$\mu_{\text {eff,wall }}[1]$ & 53.18 & 8.16 \\
\hline $\begin{array}{c}\nu_{\text {corner }} \cdot 10^{-12} \\
{[\mathrm{~kg} / \mathrm{m} \cdot \mathrm{s} \cdot \mathrm{Pa}]}\end{array}$ & 1.05 & 6.29 \\
\hline$\mu_{\text {eff,corner }}[1]$ & 46.75 & 7.22 \\
\hline
\end{tabular}

According to results presented in Table 2, 8.94\% difference occurred between the thermal transmittance of PUR and MW filled walls. The linear thermal transmittance for the wall corner joints shows even smaller, only $3.4 \%$ differences. From only these results, we could hardly compare the moisture transfer performance of the constructions, because the results of the compared two walls and corners made of differently filled masonry blocks do not show great differences. In the case of the adjoining straight walls, the moisture transmittances were show significant differences. These values obviously cannot be produced solely by thermal analysis. It can be seen that the masonry wall built from mineral wool filled blocks can pass about 6.43 times more moisture under unit time and pressure than PUR foam filled walls. From these results, we can further calculate the effective water vapour diffusion resistance factor of the walls, by dividing the water vapour permeability of air with the moisture transmittance of a one metre section of the wall. In this study, I used the formula of temperature dependent water vapour permeability of air, depending on the absolute average ambient temperature of the blocks, which gave $\delta_{\mathrm{a}}=1.95 \cdot 10^{-10} \mathrm{~kg} / \mathrm{msPa}$. On the basis of the results shown in Table 2, we can see that in case of MW filler, the water vapour diffusion resistance is between $10 / 5$, which is the standardized value for masonry blocks according to MSZ EN 1745. Therefore, it seems that it can be used in simplified calculations (i.e. Glaser method). However, in the case of PUR filled blocks, the effective water vapour diffusion resistance factor is more than 5 times the dry cup value. Therefore, in the case of PUR filler, using 10/5 as an assumed value leads to calculation errors. We can conclude this, that the practice, when product manufacturers takes $\mu$ value of fired clay from the standard as the water vapour diffusion resistance factor of masonry blocks may differ significantly from the value obtained by a proper hygrothermal simulation, and it definitely depends on the moisture behaviour of the filler material. Evaluating the linear moisture transmittances, the results show more than 6 times difference compared to each other. This means that in corner joints made of MW filled masonry blocks, 6 times more moisture can pass through because of moisture bridging in the corner. Calculating the effective water vapour diffusion resistance factor based on the moisture transmittance of the wall corner, the values decreased by around $12 \%$, respectively. This means that the moisture bridging effect in the wall corner reduced the effective water vapour diffusion resistance factor of the adjoining walls.

Fig. 9 shows the moisture transmittance values month by month. It is clearly visible that walls made of masonry blocks filled with thermal insulations with high vapour permeability (AG, MW and EXP) have significantly higher moisture transmittances, especially in during summer, than thermal insulations with low vapour permeability (PUR, EPS). This effect also visible on the effective water vapour diffusion resistance factor of the walls with different thermal insulations (Fig. 10), and this form of evaluation shows the differences between the PUR and EPS filled masonry blocks than $\mathrm{M}$ values. 


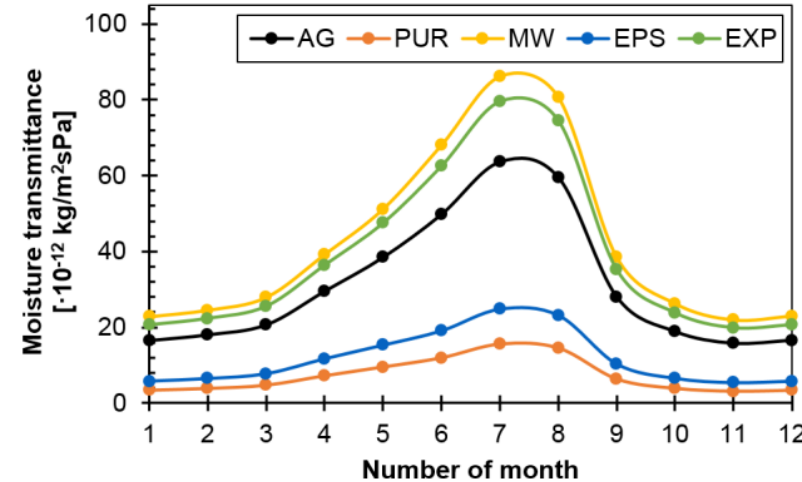

Figure 9: Monthly moisture transmittance of walls.

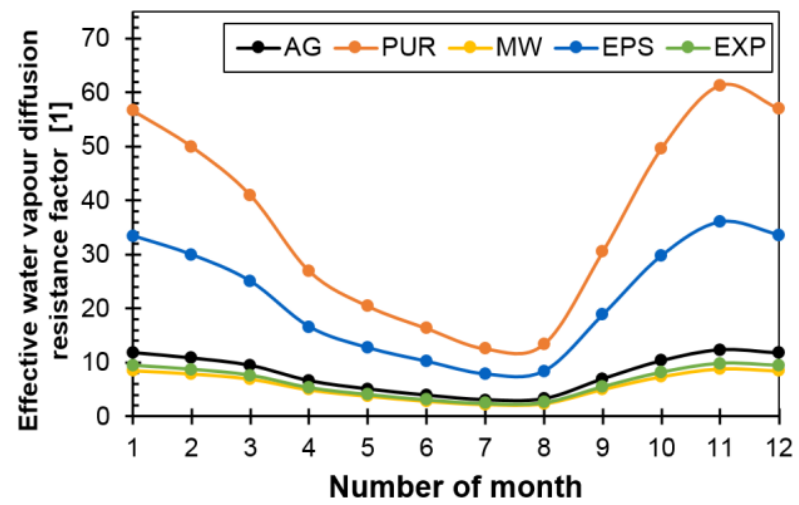

Figure 10: Monthly effective water vapour diffusion resistance factor of walls.

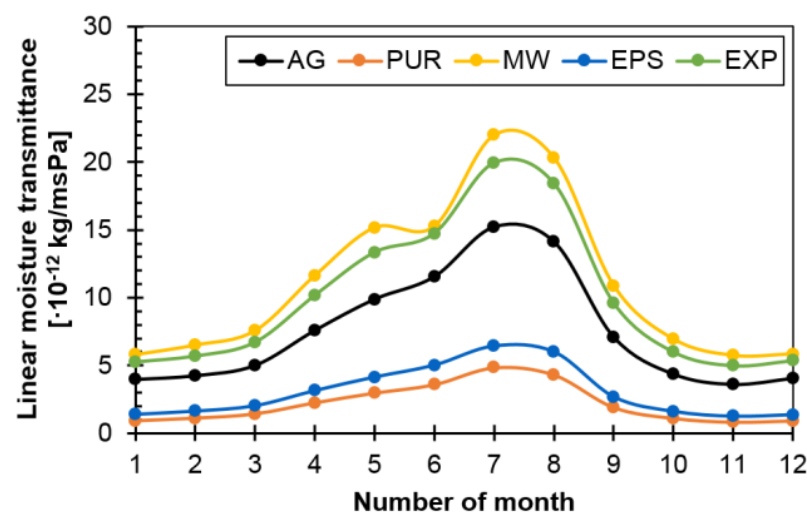

Figure 11: Monthly linear moisture transmittance of wall corners.

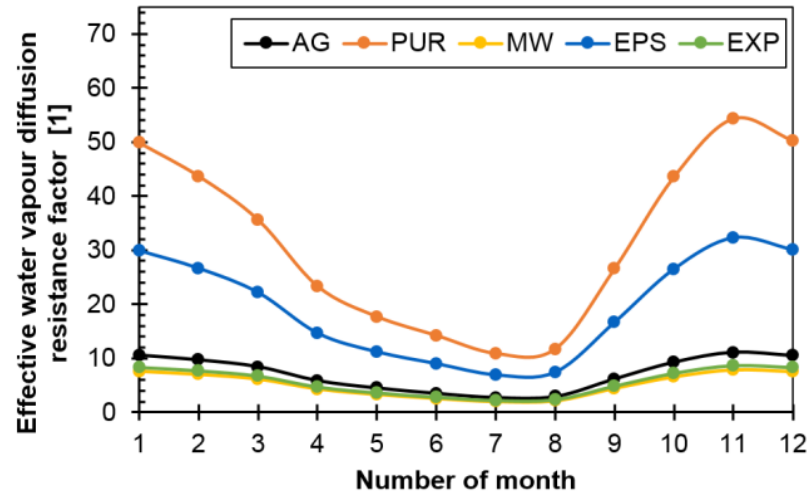

Figure 12: Monthly effective water vapour diffusion resistance factor of wall corners
Monthly based linear moisture transmittances of wall corners are illustrated by Fig. 11. The $v$ values follow the same trends as $M$ values, there is significant differences visible between the thermal insulation materials based on their hygrothermal behaviour.

This presented methodology can be used to evaluate any kind of building construction joint, e.g. to compare different moisture sealing solutions. Additional moisture in building constructions increase the thermal conductivity of the materials, therefore moisture bridges can increase the effect of thermal bridges as well. Using $M$ and $v$ values can be an effective way to evaluate the hygrothermal performance of building constructions.

\section{Conclusion}

In the presented paper, I introduced a new approach to evaluate the moisture performance of building constructions by using monthly based hygrothermal simulations and demonstrated it by calculating moisture transmittance and linear moisture transmittance and the effective water vapour diffusion resistance factor of walls and wall corner joints made of thermal insulation filled masonry blocks in Budapest climate.

- I showed that, while the thermal transmittance in the heating season showed only $8.9 \%$ difference between walls made of polyurehtane foam and mineral wool filed masonry blocks, and the linear thermal transmittance showed even smaller, only $3.4 \%$ difference, the moisture transmittance was 6.4 times and the linear moisture transmittance was 6 times higher in case of mineral wool filler compared to polyurethane foam.

- I showed that moisture transmittance, linear moisture transmittance and the effective water vapour diffuison resistance factor of the wall and wall corner joints varies significantly on monthly basis. Highest moisture transport can be found in summer months, therefore the highest effective water vapour diffusion resistance factors are observable in the heating season. Filler materials with low vapour permeability (PUR, EPS) decrease their resistance factors by greater amount than insulations with high vapour permeability (AG, MW, EXP).

- I showed that the effective water vapour diffusion resistance factor of wall corners are lower because of moisture bridging effect, and also demonstrated that if the vapour permeability of the filler material is higher than the fired clay shell, then using the values of fired clay could be acceptable, how the current standard allows it. However, if the permeability of the filler is lower, using the values of fired clay as substitution leads to calculation errors in the heating season.

- By calculating and analysing linear moisture transmittances and effective water vapour diffusion resistance factors of building construction joints, the excess moisture permeability of the joints due to moisture bridging effect can be examined and it can help to reduce design failures in the constructions. 


\section{Acknowledgement}

Project FK 128663 has been implemented with the support provided from the National Research, Development and Innovation Fund of Hungary, financed under the FK_18 funding scheme. Support of grant BME FIKP-VÍZ by EMMI is kindly acknowledged.

\section{References}

Bakonyi, D. and Dobszay, G. (2014) A proposed methodology for the improvement of the simplified calculation of thermal bridges for well typified facades, Periodica Polytechnica Civil Engineering, 58(4), pp. 309-318.

Gao, G. et al. (2017) Wind-driven rain on a building façade in urban environment, Procedia Engineering. Elsevier, 205, pp. 1678-1684.

Hou, S. et al. (2017) Coupled heat and moisture transfer in hollow concrete block wall filled with compressed straw bricks, Energy and Buildings. Elsevier, 135, pp. 74-84.

Krejčí, T. et al. (2017) Numerical analysis of coupled heat and moisture transport in masonry, Computers \& Mathematics with Applications. Pergamon, 74(1), pp. 229-248.

Künzel, H. M. (1995) Simultaneous Heat and Moisture Transport in Building Components One- and twodimensional calculation using simple parameters, Physics. IRB Verlag.

Maděra, J. et al. (2017) Parallel modeling of hygrothermal performance of external wall made of highly perforated bricks, Advances in Engineering Software, 113, pp. 47-53.
Nagy, B. and Orosz, M. (2015) 'Optimized Thermal Performance Design of Filled Ceramic Masonry Blocks', Applied Mechanics and Materials, 797, pp. 174-181.

Nagy, B. and Stocker, G. (2019) Numerical Analysis of Thermal and Moisture Bridges in Insulation Filled Masonry Walls and Corner Joints, Periodica Polytechnica Civil Engineering, 63(2),

Nagy, B. and Tóth, E. (2016) Hygrothermal behaviour of hollow and filled ceramic masonry blocks, in International RILEM Conference on Materials, Systems and Structures in Civil Engineering 2016. Lyngby, Denmark, pp. 279-288.

Pavlik, Z. et al. (2002) System for Testing the Hygrothermal Performance of Multi-Layered Building Envelopes, Journal of Thermal Envelope and Building Science. Sage PublicationsSage CA: Thousand Oaks, CA, 25(3), pp. 239-249.

Pavlík, Z. et al. (2015) Laboratory Critical Experiment Simulating Long-Term Exposure to External Environment: A Hollow Brick Block with MineralWool-Fiber Cavity Filler, in International Conference on Civil, Materials and Environmental Sciences (CMES 2015), pp. 40-42.

Szkordilisz, F. and Zöld, A. (2016) Effect of Vegetation on Wind-Comfort, Applied Mechanics and Materials, 824, pp. 811-818.

Zach, J. et al. (2013) Study of hygrothermal behavior of advanced masonry components made with utilization of secondary row materials, in 2nd CENTRAL EUROPEAN SYMPOSIUM ON BUILDING PHYSICS. Vienna, pp. 169-174 